\title{
Synthesis of Poly[(3-(6-(9-anthracenylmethoxy)hexyl)thiophene)- co-(3-(6-bromohexyl)thiophene)] Postfunctionalized from Poly(3-(6-bromohexyl)thiophene): A Comparative Study of the Base Polymer with Its Chlorinated Analogous
}

\author{
F. R. Díaz-Alzamora, ${ }^{1}$ M. A. del Valle, ${ }^{1}$ C. M. Núñez, ${ }^{1}$ P. P. Zamora, ${ }^{1}$ \\ J. P. Soto, ${ }^{1}$ and J. C. Bernède ${ }^{2}$ \\ ${ }^{1}$ Laboratorio de Polímeros, Facultad de Química, Pontificia Universidad Católica de Chile, Vicuña Mackenna 4860, \\ Macul, Santiago, Chile \\ ${ }^{2}$ Faculté des Sciences et dês Techniques, Universite de Nantes Atlantique, LAMP, EA 3829, 2 rue de la Houssieniere, \\ BP 922098, 44000 Nantes, France
}

Correspondence should be addressed to F. R. Díaz-Alzamora, fdiaz@uc.cl

Received 15 September 2008; Revised 8 January 2009; Accepted 8 March 2009

Recommended by Bernabé L. Rivas

A synthetic method based on the postfunctionalization of a reactive homopolymer precursor, which allows for the preparation of different copolymers derived from poly(3-alkylthiophene), was studied. Although these groups decrease the solubility of the resultant material, they enable controlling the degree of substitution to obtain a material with improved spectroscopic (absorption and emission) properties making them useful for the fabrication of electronic devices, for example, solar cells and light-emitting diodes. Furthermore, a comparative study of two halogenated $(\mathrm{Cl}$ and $\mathrm{Br})$ reactive poly $(3-\omega$-haloalkyl)thiophenes was carried out.

Copyright (c) 2009 F. R. Díaz-Alzamora et al. This is an open access article distributed under the Creative Commons Attribution License, which permits unrestricted use, distribution, and reproduction in any medium, provided the original work is properly cited.

\section{Introduction}

Among the great number of conjugated polymers, poly(3alkylthiophene)s stand out due to their outstanding properties and potential applications. High solubility, processability, electroactivity, and stability, among others, are some of their noteworthy properties [1-5]. In addition, rechargeable batteries, electrochromic devices, chemical and optical sensors [6], positive charge carrier in organic light-emitting diodes (OLEDs) [7-10], and nonlinear optical materials [11-13], among others, are some of their most prominent applications in which they can be utilized.

All these properties call for a highly orderly polymer. The regioregularity of poly(3-alkylthiophene)s is very important and, therefore, it is necessary to know their regioregularity degree. The electrical and optical properties of polyalkylthiophenes fuctionalized in their alkyl chains present great sensitivity to electrochemical or chemical perturbations $[14,15]$.
Due to these properties, polyalkylthiophenes functionalized in their alkyl chain have been prepared with interesting applications as chemical sensors [16].

The development of methods for the synthesis of substituted pyrrole, and particularly monomers of thiophene, has been reported using substituents such as crown-ethers [17], metallocenes, aminoacids and peptides, and proteins and enzymes [18-21]. However, the introduction of substituent groups into the pyrrole and thiophene monomers for their subsequent polymerization has led to materials with very low electrical conductivity. This has been ascribed to steric interactions among neighboring groups that decrease the conjugation of the polymer and thus hinders the electronic transference through the main chain of pyrrole and thiophene leading to a low conductivity [22].

To overcome this drawback many workers have focussed their effort on the preparation of functionalized oligomers, for example, sexithiophenes [23], terthiophene, and 


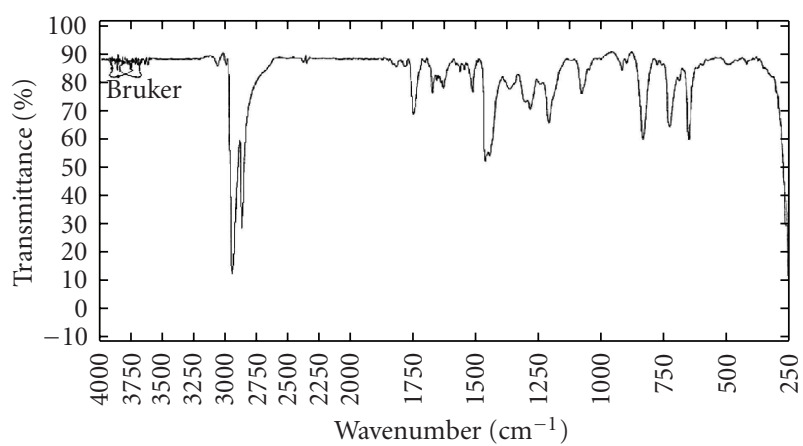

FIGURE 1: FT-IR spectrum of poly[3-(6-clorohexyl)thiophene].
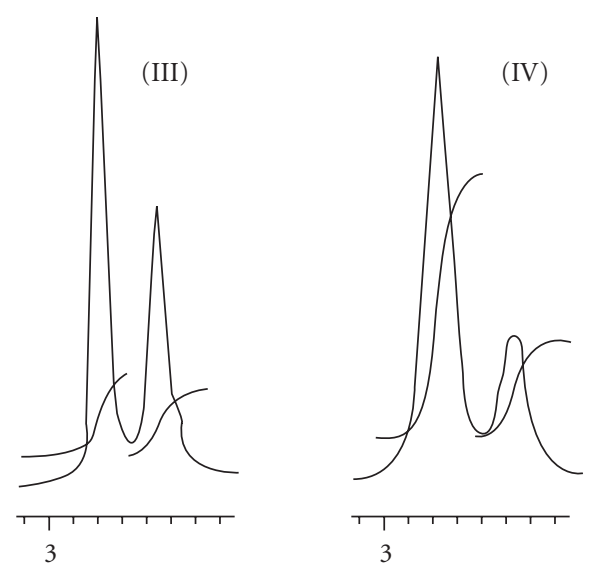

Figure 2: ${ }^{1} \mathrm{H}-\mathrm{RMN}$, relative areas of the signal attributed to $\mathrm{CH}_{2}$ adjacent to the thiophene ring for poly[3-(6-clorohexyl)thiophene] (III) and poly[3-(6-bromohexyl) thiophene] (IV).

ditienylpyrrol [24]. As a result of the polymerization of these small oligomeric units a copolymer is obtained wherein the substituent units are separated, minimizing the steric interaction among adjacent functional groups. The resultant polymer presents a better conjugation along the heterocyclic chain and high conductivity. [25]

Various strategies exist for the preparation of this kind of polymers; the most utilized being the preparation of monomeric units already functionalized for their subsequent polymerization. However, many of these functional groups are incompatible with the polymerization process generating undesirable oxidations, along with low molecular weight of the polymer, or a total hindrance of the polymerization $[26,27]$. The choice of the method of polymerization is very important if a regular material without modifications into the substituent group is sought. The most utilized method is the direct chemical oxidation using $\mathrm{FeCl}_{3}[28,29]$. Nevertheless, a very efficient method for controlling the oxidation is the electropolymerization, affording substituted polymers almost without modification in the substituent groups [30]. Another very efficient way to overcome this problem is the preparation of poly-alkylthiophenes with the
TABLE 1: Conductivity of doped and undoped polymers (III), (IV), (V).

\begin{tabular}{lcc}
\hline Polymer & Undoped $(\mathrm{ms})$ & Doped $(\mathrm{ms})^{*}$ \\
\hline (III) & $4.0 \cdot 10^{-11}$ & $1.4 \cdot 10^{-6}$ \\
(IV) & $2.0 \cdot 10^{-9}$ & $1.0 \cdot 10^{-4}$ \\
(V) & $6.0 \cdot 10^{-10}$ & $2.0 \cdot 10^{-3}$ \\
\hline
\end{tabular}

$* \mathrm{I}_{2}$ was utilized as doping agent

capacity of being functionalized. This is the case of poly(3( $\omega$-haloalkyl)thiophene), which has been successfully postfunctionalized with almost quantitative conversion [31]. This allows for the combination between the properties of the conjugated polymer and the substituent group of interest.

In the present work the synthesis, characterization, properties, and the two-step preparation of its monomer unit [32], that permits a swift and facile preparation of the polymer, of poly(3-(6-bromohexyl)thiophene) are reported. In addition, a comparative study between poly(3-(6-chlorohexyl)thiophene) and poly(3-(6-bromohexyl)thiophene) was performed. The latter compound was prepared following the procedure described by Iraqi et al. [33]. Finally, poly[(3(6-(9-anthracenylmethoxy)hexyl)thiophene)-co-(3-(6-bromohexyl)thiophene)] was synthesized by postfunctionalization of poly(3-(6bromohexyl)thiophene), which shows the best regioregular properties of the two surveyed halogenated polymers.

\section{Experimental}

All solvents and reagents utilized in this work were purchased from Aldrich and used as received. ${ }^{1} \mathrm{H}-\mathrm{NMR}$ spectra were recorded on an ACP Bruker 200 Spectrometer using TMS as internal standard. FTIR spectra of the polymers were recorded on a Bruker Vector 22 FT-IR spectrophotometer using $\mathrm{KBr}$ pellet or films. Molecular weights were determined by gel permeation chromatography and polystyrene as standard reference on a Lab Flow 2000 HPLC chromatograph provided with a column of Phenogel and a (UVIS 200) UVVis detector at $263 \mathrm{~nm}$. The mobile phase was toluene at a flow rate of $1.0 \mathrm{~mL} \cdot \mathrm{min}^{-1}$. Conductivity measurements were conducted at room temperature on pellets of the polymer ( $24000 \mathrm{psi})$ by the four-probe method on an Elchema Electrometer CM 508. UV spectra were recorded on a Gena Specord 40 spectrophotometer.

2.1. Synthesis of [3-(6-chlorohexyl)thiophene]. $2.50 \mathrm{~g}$ (12 $\mathrm{mmol}$ ) of 1-bromo-6-chlorohexane were added to $50 \mathrm{~mL}$ of ethyl ether containing $0.27 \mathrm{~g}$ of $\mathrm{Mg}$ turnings. The mixture was chilled to $0{ }^{\circ} \mathrm{C}$ under $\mathrm{N}_{2}$ and constant stirring for 12 hours. The Grignard reagent prepared was added to a new solution containing $100 \mathrm{~mL}$ of anhydrous ethyl ether, $1.8 \mathrm{~g}(11 \mathrm{mmol})$ of 3-bromothiophene, and $0.4 \mathrm{mmol}$ of $\mathrm{Ni}(\mathrm{dppp}) \mathrm{Cl}_{2}$ as catalyst. The mixture was boiled for 12 hours under $\mathrm{N}_{2}$. After cooling at room temperature, $40 \mathrm{~mL} \mathrm{HCl}$ and $50 \mathrm{~mL} \mathrm{H}_{2} \mathrm{O}$ were added, and the organic phase was separated using a separator funnel. The organic phase was dried $\left(\mathrm{Na}_{2} \mathrm{SO}_{4}\right)$ and the solvent was evaporated at low pressure. 


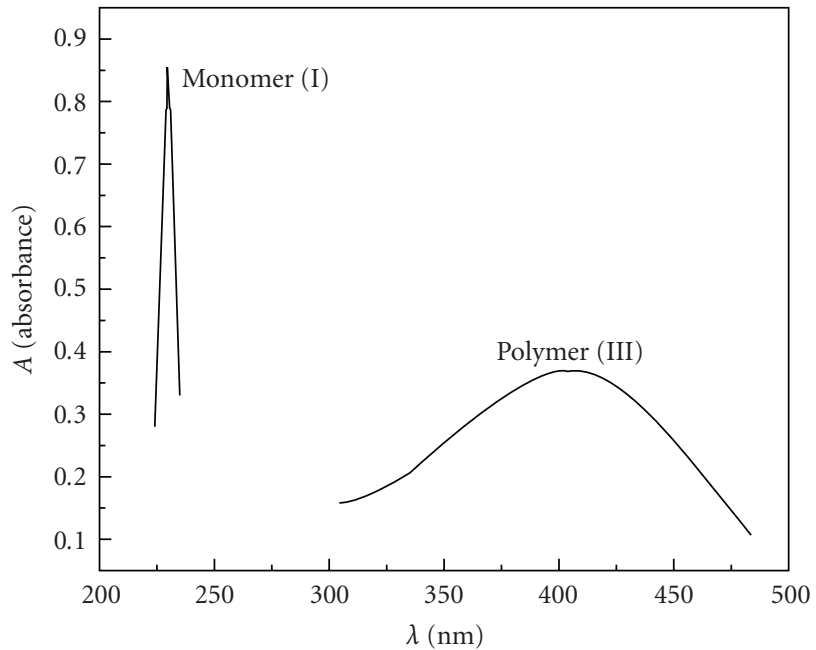

(a)

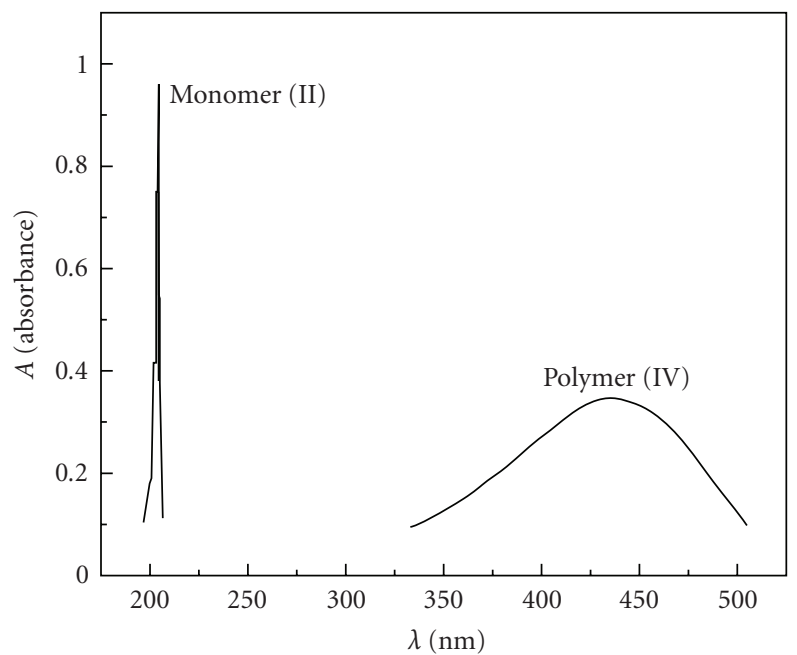

(b)

Figure 3: UV-Vis spectra in $\mathrm{CHCl}_{3}$ for monomers (I), (II) and polymers (III), (IV).

TABLE 2: Characterization of the polymers.

\begin{tabular}{lcccccc}
\hline Polymer & Yield\% & Composition\% (a) & HT \% (b) & Solubility $(\mathrm{c})$ & $\mathrm{M}_{n}(\mathrm{~g} / \mathrm{mol})(\mathrm{d})($ average $)$ & $\mathrm{M}_{w} / \mathrm{M}_{n}(\mathrm{~d})(\mathrm{average})$ \\
\hline (III) & 59 & - & 55 & $\mathrm{t}$ & 3.000 & 3.2 \\
(IV) & 61 & - & 73 & $\mathrm{t}$ & 40.000 & 2.3 \\
(V) & - & 10 & 73 & $\mathrm{p}$ & - & - \\
\hline
\end{tabular}

(a) Molar percent of substituent, (b) head-to-tail regioregularity, in dyads, determined by ${ }^{1} \mathrm{H}$-RMN spectroscopy, (c) t: Wholly soluble in common organic solvents; p: Partially soluble, (d) number average molar mass, $\mathrm{M}_{n}$ : Average polydispersity index, $\mathrm{M}_{w} / \mathrm{M}_{n}$, determinated by GPC using polystyrene as standard.

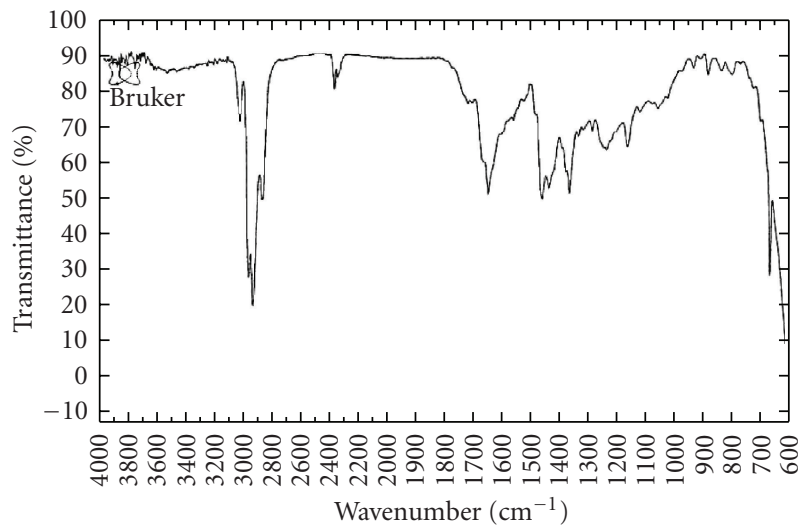

FIGURE 4: FT-IR spectrum of poly[(3-(6-(9-anthracenyloxy)hexyl) thiophene)-co-(3-(6-bromohexyl)thiophene)] (V).

The residue was purified by column chromatography on silica-gel (hexane). The product was a colorless liquid, yield $1.49 \mathrm{~g}(67 \%)$, bp. $172{ }^{\circ} \mathrm{C}$, at $0.1 \mathrm{~mm} \mathrm{Hg} .{ }^{1} \mathrm{H}-\mathrm{NMR}\left(\mathrm{CDCl}_{3}\right.$, $200 \mathrm{MHz}) \delta 1.28-1.48(4 \mathrm{H}, \mathrm{m}), 1.61(2 \mathrm{H}, \mathrm{m}), 1.82(2 \mathrm{H}$, $\mathrm{m}), 2.60(2 \mathrm{H}, \mathrm{t}, J=8 \mathrm{~Hz}), 3.55(2 \mathrm{H}, \mathrm{t}, J=7 \mathrm{~Hz}), 6.89(2 \mathrm{H}$, m), $7.18(2 \mathrm{H}, \mathrm{m}) ;{ }^{13} \mathrm{C}-\mathrm{RMN}\left(\mathrm{CDCl}_{3}, 200 \mathrm{MHz}\right) \delta 26.7,28.5$, 30.1, 30.2, 32.4, 45.1, 119.9, 125.1, 128.2, 142.9. FTIR (film, $\left.\mathrm{cm}^{-1}\right): 3089,2931,2856,1541,1460,1417,834,826,759$, 644. Calculated elemental analysis for $\mathrm{C}_{10} \mathrm{H}_{15} \mathrm{ClS}$ : C, 59.24; H, 7.46; S, 15.81. Found: C, 59.21; H, 7.42; S, 15.78 .

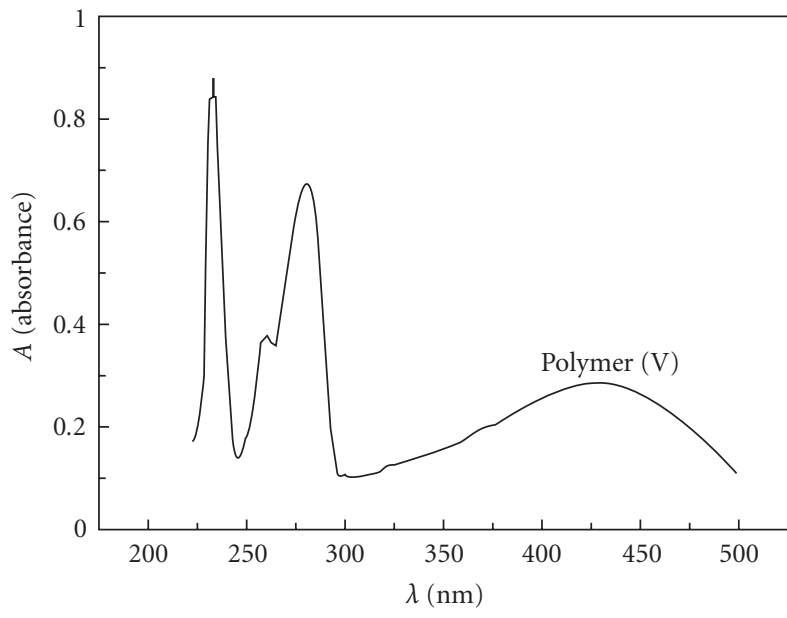

FIGURE 5: UV-Vis spectrum of copolymer (V) in $\mathrm{CHCl}_{3}$.

2.2. Description of 3-(6-bromohexyl)thiophene synthesis. As mentioned above, the method utilized was that of Iraqi [33] with $60 \%$ yield, based upon 3-bromothiophene. Spectra of the product are as follows. ${ }^{1} \mathrm{H}-\mathrm{RMN}\left(\mathrm{CDCl}_{3}, 200 \mathrm{MHz}\right) \delta$ $1.28-1.48(4 \mathrm{H}, \mathrm{m}), 1.62(2 \mathrm{H}, \mathrm{m}), 1.82(2 \mathrm{H}, \mathrm{m}), 2.60(2 \mathrm{H}$, $\mathrm{t}, J=8 \mathrm{~Hz}), 3.35(2 \mathrm{H}, \mathrm{t}, J=7 \mathrm{~Hz}), 6.86-6.92(2 \mathrm{H}, \mathrm{m}), 7.10-$ $724(1 \mathrm{H}, \mathrm{m}) ;{ }^{13} \mathrm{C}-\mathrm{RMN}\left(\mathrm{CDCl}_{3}, 200 \mathrm{MHz}\right) \delta 27.9,28.3,30.1$, $30.3,32.7,33.9,119.9,125.1,128.3,142.8$. FTIR (film, $\mathrm{cm}^{-1}$ ): $3103,3053,3004,2931,2856,1537,1460,1438,1410,1258$, 


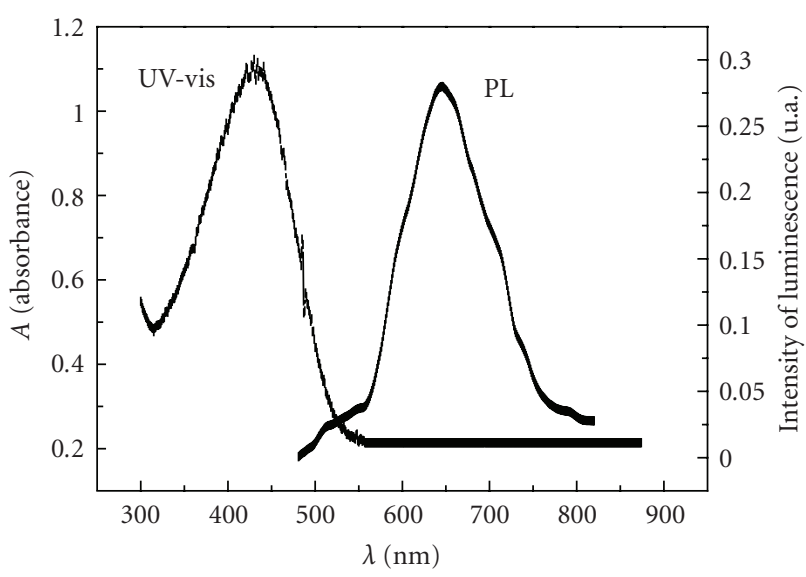

Figure 6: Photoluminescent and UV-vis spectra of copolymer [5] in $\mathrm{CHCl}_{3}$.

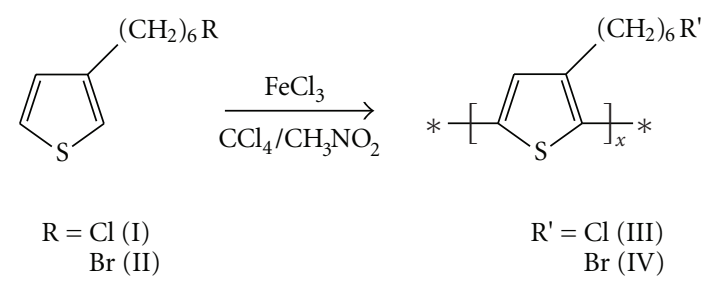

Scheme 1: Synthesis of poly[3-(6-clorohexyl)thiophene] and poly[3-(6-bromohexyl)thiophene].

$1238,1153,1080,860,834,773,685,635,561$. Calculated elemental analysis for $\mathrm{C}_{10} \mathrm{H}_{15} \mathrm{BrS}$ : C, 48.59; H, 6.12; S, 12.97 . Found: C, 48.56; H, 6.09; S, 12.95 .

2.3. Synthesis of poly [3-(6-chlorohexyl)thiophene]. A solution containing $1.60 \mathrm{~g}(9.6 \mathrm{mmol}) \mathrm{FeCl}_{3}$ in $10 \mathrm{~mL} \mathrm{CH}_{3} \mathrm{NO}_{2}$ was slowly poured during 20 minutes into a solution of $0.5 \mathrm{~g}$ (2.4 mmol) of 3-(6-clorohexyl)thiophene in $30 \mathrm{~mL} \mathrm{CCl}_{4}$. The mixture was stirred for 6 hours at room temperature and then filtered under vacuum. The solid was Soxhlet extracted with methanol and dried at $60{ }^{\circ} \mathrm{C}$. The product was a red solid, yield $0.28 \mathrm{~g}(59 \%)$. Spectral characterizations were as follows: ${ }^{1} \mathrm{H}-\mathrm{RMN}\left(\mathrm{CDCl}_{3}, 200 \mathrm{MHz}\right) \delta 1.30-1.85$ $(8 \mathrm{H}, \mathrm{m}), 2.50-2.90(2 \mathrm{H}, \mathrm{m}), 3.52(2 \mathrm{H}, \mathrm{m}), 6.93,6.99$, 7.02, $7.09(1 \mathrm{H}, 4 \mathrm{~s}) ;{ }^{13} \mathrm{C}-\mathrm{RMN}\left(\mathrm{CDCl}_{3}, 200 \mathrm{MHz}\right) \delta 28.0$, 28.6, 29.3, 30.3, 32.7, 34.0, 128.6, 130.6, 133.7, 139.6 . FTIR ( $\mathrm{KBr}, \mathrm{cm}^{-1}$ ): 3057 (ArCH, stretching), 2927 y 2853 ( $\mathrm{sp}^{3} \mathrm{CH}$ stretching), 1671, 1509 y 1458 (ArC-C, stretching corresponding to combination bands of heterocycles), 1440 $(\mathrm{C}=\mathrm{C}$, symmetric stretching of the thiophene ring), 830 (C$\mathrm{H}$ out-of-plane twist of thiophene 2,3,5-trisubstituted), 726 (methylene groups rocking vibration), 648 (C-Cl, stretching), Figure 1.

2.4. Synthesis of poly[3-(6-bromohexyl)thiophene]. The preparation of this compound was that described by
Lanzi et al. [34]. $1.60 \mathrm{~g}(9.6 \mathrm{mmol})$ of anhydrous $\mathrm{FeCl}_{3}$ dissolved in $10 \mathrm{~mL} \mathrm{CH} \mathrm{CH}_{3} \mathrm{NO}_{2}$ was slowly poured during 20 minutes into a solution of $0.6 \mathrm{~g}(2.4 \mathrm{mmol})$ of 3-(6clorohexyl)thiophene in $30 \mathrm{~mL} \mathrm{CCl}$. The mixture was stirred for 6 hours at room temperature and then vacuum filtered. The solid was Soxhlet extracted with methanol and dried at $60^{\circ} \mathrm{C}$. The product was a red solid, yield $1.4 \mathrm{~g}$ (61\%). The spectral data were ${ }^{1} \mathrm{H}-\mathrm{RMN}\left(\mathrm{CDCl}_{3}, 200 \mathrm{MHz}\right)$ $\delta 1.30-1.95(8 \mathrm{H}, \mathrm{m}), 2.50-2.90(2 \mathrm{H}, \mathrm{m}), 3.40(2 \mathrm{H}, \mathrm{m}), 6.92$, 6.98, 7.01, $7.08(1 \mathrm{H}, 4 \mathrm{~s}) ;{ }^{13} \mathrm{C}-\mathrm{RMN}\left(\mathrm{CDCl}_{3}, 200 \mathrm{MHz}\right) \delta$ 28.0, 28.6, 29.3, 30.3, 32.7, 33.9, 128.7, 130.6, 133.7, 139.6. FTIR $\left(\mathrm{KBr}, \mathrm{cm}^{-1}\right): 3054,2932,2856,1661,1514,1461,1440$, $832,728,648,562$.

\subsection{Synthesis of poly[(3-(6-(9-anthracenylmethoxy)hexyl)} thiophene)-co-(3-(6-bromohexyl) thiophene)]. To a solution of $0.4 \mathrm{~g}(1.6 \mathrm{mmol})$ of poly[3-(6-bromohexyl)thiophene] in $30 \mathrm{~mL}$ of anhydrous THF, $0.036 \mathrm{~g}(0.16 \mathrm{mmol})$ of sodium 9-anthracenyl methoxy (previously prepared from 9-anthracenyl methanol and $\mathrm{NaH}$ in THF) was added. This solution was stirred for 24 hours at $60{ }^{\circ} \mathrm{C}$ in the presence of $0.026 \mathrm{~g}(0.16 \mathrm{mmol})$ of KI. After cooling at room temperature, $30 \mathrm{~mL}$ methanol was added and the solid was filtered and Soxhlet extracted with methanol. The product, a red solid, was dried at $60{ }^{\circ} \mathrm{C}$ yielding 0.45 g. FTIR $\left(\mathrm{KBr}, \mathrm{cm}^{-1}\right): 3100$ ( $\mathrm{sp}^{2} \mathrm{C}-\mathrm{H}$ stretching), 2934 y 2858 ( $\mathrm{sp}^{3}$ C-H stretching), 1647 y $1442(\mathrm{C}=\mathrm{C}$ aromatic stretching), 1380 (symmetric in-plane $\mathrm{C}=\mathrm{C}$ stretching of thiophene ring), 1250 and 1060 (ArC-O-C-al, symmetric stretching), 835 (2,3,5-trisubstituted thiophene C-H out-ofplane bending vibration), 690 (methylene groups rocking vibration), Figure 4.

\section{Results and Discussion}

Using the monomers 3-(6-clorohexyl)thiophene and 3-(6bromohexyl)thiophene as starting materials, the respective polymers were prepared. With the purpose of comparing the prepared compounds, similar reaction conditions, oxidizing agent, monomer concentration, and time of reaction were utilized. Thus, we expected polymers with analogous characteristics, however the obtained products showed different molar mass and regioregularity, Schemes 1 and 2.

The regioregularity of poly[3-(6-clorohexyl)thiophene] and poly[3-(6-bromohexyl) thiophene] was determined by ${ }^{1} \mathrm{H}-\mathrm{NMR}$ spectroscopy [35]. To this end, however, the relative ratio of the areas ascribed to $\mathrm{CH}_{2}$ adjacent to the thiophene ring has to be determined, Figure 2.

Comparison of the results obtained for polymers (III) and (IV) shows that when $\mathrm{Cl}$ is used at the end of the alkyl chain, as monomer unit, a polymer with lower average molar mass and regioregularity than that of the brominated analogous is produced. This has been attributed to the smaller size of the halogen, $\mathrm{Cl}$, which increases the probability of approaching of the monomer units, due to a lower steric interaction amidst them. On the other hand, when $\mathrm{Br}$ is employed as halogen at the end of the alkyl chain 

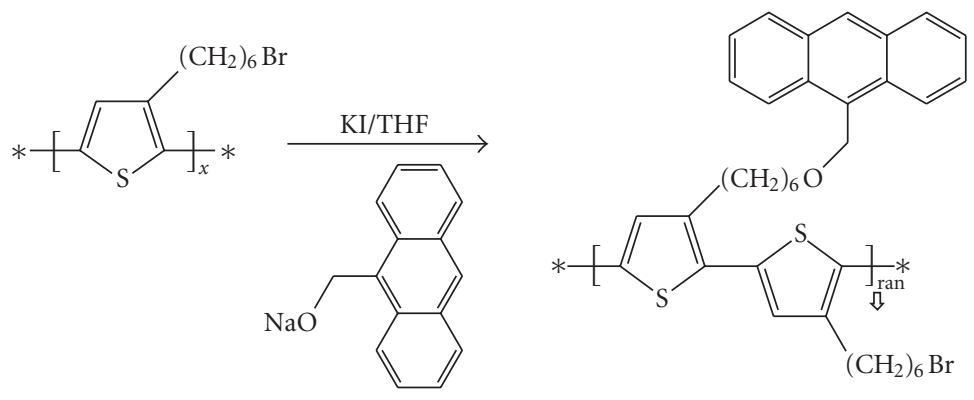

(V)

Scheme 2: Synthesis of poly[(3-(6-(9-anthracenyloxy)hexyl)thiophene)-co-(3-(6-bromohexyl)thiophene)].

the steric interaction of the monomers increases owing to the greater size of the halogen, decreasing the probability of forming 2,2' head-to-head ( $\mathrm{H}-\mathrm{H})$ bonds and increasing the probability of forming 2,5 ' head-to-tail $(\mathrm{H}-\mathrm{T})$ bonds. This becomes evident by the difference in regioregularity of polymers (III) and (IV), Table 2 .

Synthesis of polymers (III) and (IV) was carried out in a similar way producing compounds with similar solubility in organic solvents, such as THF, $\mathrm{CHCl}_{3}, \mathrm{CH}_{2} \mathrm{Cl}_{2}$, ethyl ether, and $\mathrm{CCl}_{4}$. FT-IR spectra are also similar for these compounds, however UV-Vis spectra in $\mathrm{CHCl}_{3}$ show different absorption maxima, 412 and $43 \mathrm{~nm}$, respectively, Figure 3. This difference suggests that the conjugation in the main chain of thiophene is greater in polymer (IV). This finding agrees well with the average molecular weight, $\mathrm{M}_{w}$, determined for polymers (III) and (IV): the brominated derivative (IV) shows a higher average molecular weight, $\mathrm{M}_{w}$, 40000.

Polymer (IV) was employed as starting material for the synthesis of copolymer ( V) because of its greater regioregularity, HT. The degree of substitution of terminal bromine atoms of the alkyl chain is conducted by controlling the added amount of sodium 9-anthracenyl metoxide. The low nucleophilicity of the substituent chromophore group makes the use of KI and sodium salt of 9-anthracenyl methanol necessary. When 20 or $30 \%$ of the substituent (sodium 9-anthracenyl metoxide), with respect to the number of moles of polymer (IV), was employed in the preparation of the copolymer, a sparingly soluble product was obtained; however, when $10 \%$ of the substituent was used in the postfunctionalization, a material with higher solubility than in the previous cases was produced.

Copolymer (V) is only fairly soluble in common organic solvents, hindering the determination of its average molar mass, polydispersity, and NMR spectrum. Nevertheless, its UV-Vis, photoluminescent and FT-IR spectra allow its characterization and determination of some of its interesting properties. Figure 4 depicts an FT-IR spectrum of copolymer (V).

The copolymer (V) presents a very strong absorption in the UV-Vis spectrum with a maximum at $433 \mathrm{~nm}$, Figure 5; however, when excited at that wavelength its photoluminescent spectrum shows a maximum at $654 \mathrm{~nm}$ with a low fluorescent intensity, Figure 6 , allowing to assume that a high percentage of the relaxation process occurs through a triplet state, indicating that the copolymer possesses suitable properties to be utilized in solar cells.

Table 1 lists the conductivities of doped and undoped polymers (III), (IV), and (V). The conductivities can be related to the respective regioregularities. Polymer (IV) displays a greater conductivity than polymer (III), which is consistent with the fact that the conductivity is greater for highly ordered systems, enhancing thus the coplanarity of thiophene rings in the doped state.

On the other hand, it is likely that the observed conductivity of the copolymer in the doped state being due to the presence of aromatic anthracene rings as substituent, which allows for the conduction to be accomplished by overlapping of $\pi$ systems orbitals. This is consistent with the higher conductivity found for copolymer (V).

The optical band gap of these polymers was estimated by UV-Vis and was found to be: $\left(\mathrm{CHCl}_{3}\right) 530 \mathrm{~nm}, 2.33 \mathrm{eV}$ for polymer (III), $506 \mathrm{~nm}, 2.45 \mathrm{eV}$ for polymer (IV), and $539 \mathrm{~nm}, 2.30 \mathrm{eV}$ for copolymer (V), this presents a lower band gap than its base polymer.

The decrease of the band gap in conductive polymers occurs when the number of monomer units of thiophene increases in the polymeric chain. However, in the present case it has been ascribed to a higher order and stiffness conferred by the substituent group, which is responsible for many of its properties.

\section{Conclusions}

The synthesis of two novel polymers derived from thiophene has been described along with their characterization and determination of the average molar mass, regioregularity, conducting properties, and optical bandgap. The low solubility of copolymer (V) hinders its characterization by techniques such as FT-IR, and absorption and emission spectroscopy. The latter techniques are very important since our interest is focussed on the use of the copolymer to fabricate electronic devices, for example, solar cells, light emitting diodes, and so on. 


\section{Acknowledgments}

The authors wish to thank Fondecyt-Chile through Grant 1050953, and Conicyt doctoral fellowship 4040121 and 23060093 TTD for financial support of this research work.

\section{References}

[1] A. O. Patil, A. J. Heeger, and F. Wudl, "Optical properties of conducting polymers," Chemical Reviews, vol. 88, no. 1, pp. 183-200, 1988.

[2] J. Roncali, "Conjugated poly(thiophenes): synthesis, functionalization, and applications," Chemical Reviews, vol. 92, no. 4, pp. 711-738, 1992.

[3] D. J. Sandman, "Semiconducting polymers and their solidstate properties: are these materials semiconductors or large conjugated molecules?" Trends in Polymer Science, vol. 2, no. 2, pp. 44-55, 1994.

[4] D. Clery, "After years in the dark, electric plastic finally shines," Science, vol. 263, no. 5154, pp. 1700-1702, 1994.

[5] J. P. Soto, F. R. Díaz-Alzamora, M. A. del Valle, C. M. Núñez, and J. C. Bernède, "Synthesis of new materials based on polythiophenes substituted with mesogen groups," European Polymer Journal, vol. 42, no. 4, pp. 935-945, 2006.

[6] Y. Furukawa, "Electronic absorption and vibrational spectroscopies of conjugated conducting polymers," The Journal of Physical Chemistry, vol. 100, no. 39, pp. 15644-15653, 1996.

[7] R. J. Kline, M. D. McGehee, E. N. Kadnikova, J. Liu, and J. M. J. Fréchet, "Controlling the field-effect mobility of regioregular polythiophene by changing the molecular weight," Advanced Materials, vol. 15, no. 18, pp. 1519-1522, 2003.

[8] W. U. Huynh, J. J. Dittmer, and A. P. Alivisatos, "Hybrid nanorod-polymer solar cells," Science, vol. 295, no. 5564, pp. 2425-2427, 2002.

[9] T.-A. Chen, X. Wu, and R. D. Rieke, "Regiocontrolled synthesis of poly(3-alkylthiophenes) mediated by Rieke zinc: their characterization and solid-state properties," Journal of the American Chemical Society, vol. 117, no. 1, pp. 233-244, 1995.

[10] R. S. Loewe, S. M. Khersonsky, and R. D. McCullough, "A simple method to prepare head-to-tail coupled, regioregular poly(3-alkylthiophenes) using grignard metathesis," Advanced Materials, vol. 11, no. 3, pp. 250-253, 1999.

[11] P. N. Prasad and D. J. Williams, Introduction to Nonlinear Optical Effects in Molecules \& Polymers, John Wiley \& Sons, New York, NY, USA, 1991.

[12] L. Robitaille, M. Leclerc, and C. L. Callender, "Poly[3(alkoxyphenyl)thiophenes]: synthesis and linear and nonlinear optical properties," Chemistry of Materials, vol. 5, no. 12, pp. 1755-1761, 1993.

[13] K. G. Chittibabu, L. Li, M. Kamath, J. Kumar, and S. K. Tripathy, "Synthesis and properties of a novel polythiophene derivative with a side-chain NLO chromophore," Chemistry of Materials, vol. 6, no. 4, pp. 475-480, 1994.

[14] R. D. McCullough, "The chemistry of conducting polythiophenes," Advanced Materials, vol. 10, no. 2, pp. 93-116, 1998.

[15] L. Groenendaal, F. Jonas, D. Freitag, H. Pielartzik, and J. R. Reynolds, "Poly(3,4-ethylenedioxythiophene) and its derivatives: past, present, and future," Advanced Materials, vol. 12, no. 7, pp. 481-494, 2000.
[16] R. D. McCullough, P. C. Ewbank, and R. S. Loewe, "Selfassembly and disassembly of regioregular, water soluble polythiophenes: chemoselective ionchromatic sensing in water," Journal of the American Chemical Society, vol. 119, no. 3, pp. 633-634, 1997.

[17] H. K. Youssoufi, M. Hmyene, F. Garnier, and D. Delabouglise, "Cation recognition properties of polypyrrole 3-substituted by azacrown ethers," Journal of the Chemical Society, Chemical Communications, no. 20, pp. 1550-1552, 1993.

[18] R. Back and R. B. Lennox, "Electrochemical investigation of novel polymerizable thiophene/ferrocene conjugates," Langmuir, vol. 8, no. 3, pp. 959-964, 1992.

[19] G. Zotti, G. Schiavon, S. Zecchin, A. Berlin, A. Canavesi, and G. Pagani, "Self-assembly and electropolymerization of pyrrole- and bithiophene-n-hexyl-ferrocene molecules on ITO electrodes," Synthetic Metals, vol. 84, no. 1-3, pp. 239240, 1997.

[20] C. J. Pickett and K. S. Ryder, "Bioinorganic reaction centres on electrodes. Modified electrodes possessing amino acid, peptide and ferredoxin-type groups on a poly(pyrrole) backbone," Journal of the Chemical Society, Dalton Transactions, no. 14, pp. 2181-2189, 1994.

[21] S. Cosnier, M. Fontecave, D. Limosin, and V. Nivière, "A poly(amphiphilic pyrrole)-flavin reductase electrode for amperometric determination of flavins," Analytical Chemistry, vol. 69, no. 15, pp. 3095-3099, 1997.

[22] G. Zatti, S. Martina, G. Wegner, and A.-D. Schlüter, "Welldefined pyrrole oligomers: electrochemical and UV/vis studies," Advanced Materials, vol. 4, no. 12, pp. 798-801, 1992.

[23] W. Ten Hoeve, H. Wynberg, E. E. Havinga, and E. W. Meijer, "Substituted 2,2' : $5^{\prime}, 2^{\prime \prime}: 5^{\prime \prime}, 2^{\prime \prime \prime}: 5^{\prime \prime \prime}, 2^{\prime \prime \prime \prime}: 5^{\prime \prime \prime \prime}, 2^{\prime \prime \prime \prime \prime}$ : $5^{\prime \prime \prime \prime \prime}, 2^{\prime \prime \prime \prime \prime \prime}: 5^{\prime \prime \prime \prime \prime \prime}, 2^{\prime \prime \prime \prime \prime \prime \prime \prime}: 5^{\prime \prime \prime \prime \prime \prime \prime}, 2^{\prime \prime \prime \prime \prime \prime \prime \prime}: 5^{\prime \prime \prime \prime \prime \prime \prime \prime}, 2^{\prime \prime \prime \prime \prime \prime \prime \prime \prime \prime ~: ~}$ $5^{\prime \prime \prime \prime \prime \prime \prime \prime \prime}, 2^{\prime \prime \prime \prime \prime \prime \prime \prime \prime \prime \prime}$ - undecithiophenes: the longest characterized oligothiophenes," Journal of the American Chemical Society, vol. 113, no. 15, pp. 5887-5889, 1991.

[24] L. Groenendaal, M. J. Bruining, E. H. J. Hendrickx, et al., "Synthesis and (non)linear optical properties of a series of donoroligopyrrole-acceptor molecules," Chemistry of Materials, vol. 10, no. 1, pp. 226-234, 1998.

[25] J. P. Ferraris and M. D. Newton, "Electrochemical and optical properties of thiophene-alkylheteroaromatic copolymers," Polymer, vol. 33, no. 2, pp. 391-397, 1992.

[26] C. H. McCoy and M. S. Wrighton, "Potential-dependent conductivity of conducting polymers yields opportunities for molecule-based devices: a microelectrochemical pushpull amplifier based on two different conducting polymer transistors," Chemistry of Materials, vol. 5, no. 7, pp. 914-916, 1993.

[27] S. Sitha, K. Bhanuprakash, and B. M. Choudary, "Electrical rectification through cumulenic bridge: a computational study," Synthetic Metals, vol. 148, no. 3, pp. 227-235, 2005.

[28] S. C. Ng, Y. F. Ma, H. S. O. Chan, and Z. L. Dou, "Syntheses and characterization of electrically conductive and fluorescent poly[3-( $\omega$-bromoalkyl)thiophenes]," Synthetic Metals, vol. 100, no. 3, pp. 269-277, 1999.

[29] M. Pomerantz and M. L. Liu, "Synthesis and properties of poly[3-( $\omega$-bromoalkyl)thiophene]," Synthetic Metals, vol. 101, no. 1-3, p. 95, 1999.

[30] S. P. Mishra, R. Sahoo, A. V. Ambade, A. Q. Contractor, and A. Kumar, "Synthesis and characterization of functionalized 3,4-propylenedioxythiophene and its derivatives," Journal of Materials Chemistry, vol. 14, no. 12, pp. 1896-1900, 2004. 
[31] L. Zhai, R. L. Pilston, K. L. Zaiger, K. K. Stokes, and R. D. McCullough, "A simple method to generate side-chain derivatives of regioregular polythiophene via the GRIM metathesis and post-polymerization functionalization," Macromolecules, vol. 36, no. 1, pp. 61-64, 2003.

[32] R. Michalitsch, A. ElKassmi, A. Yassar, and F. Garnier, "A practical synthesis of functionalized alkyl-oligothiophenes for molecular self-assembly," Journal of Heterocyclic Chemistry, vol. 38, no. 3, pp. 649-653, 2001.

[33] A. Iraqi, J. A. Crayston, and J. C. Walton, "Covalent binding of redox active centres to preformed regioregular polythiophenes," Journal of Materials Chemistry, vol. 8, no. 1, pp. 3136, 1998.

[34] M. Lanzi, L. Paganin, P. Costa-Bizzarri, C. Della-Casa, and A. Fraleoni, "Facile synthesis of soluble multifunctional polyalkylthiophenes," Macromolecular Rapid Communications, vol. 23, no. 10-11, pp. 630-633, 2002.

[35] L. Zhai, R. L. Pilston, K. L. Zaiger, K. K. Stokes, and R. D. McCullough, "A simple method to generate side-chain derivatives of regioregular polythiophene via the GRIM metathesis and post-polymerization functionalization," Macromolecules, vol. 36, no. 1, pp. 61-64, 2003. 

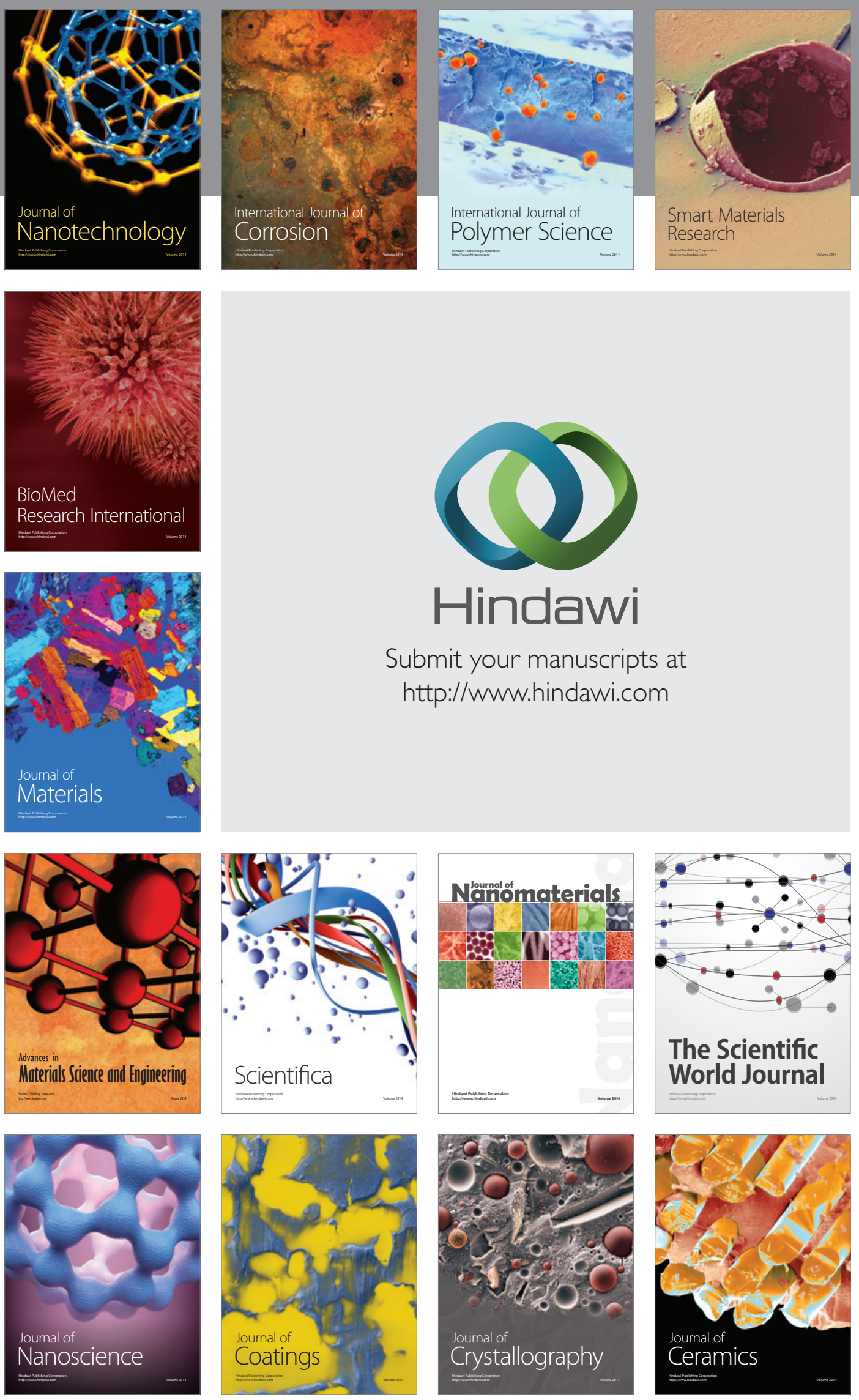

The Scientific World Journal

Submit your manuscripts at

http://www.hindawi.com

\section{World Journal}

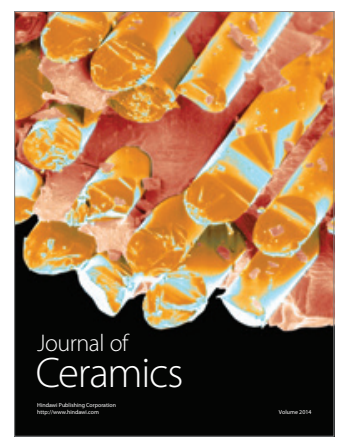

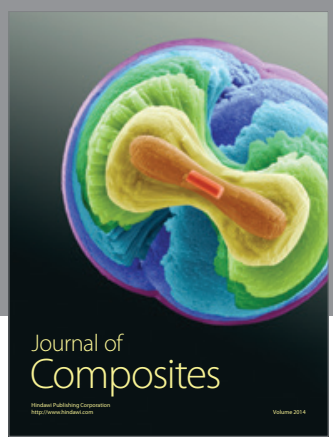
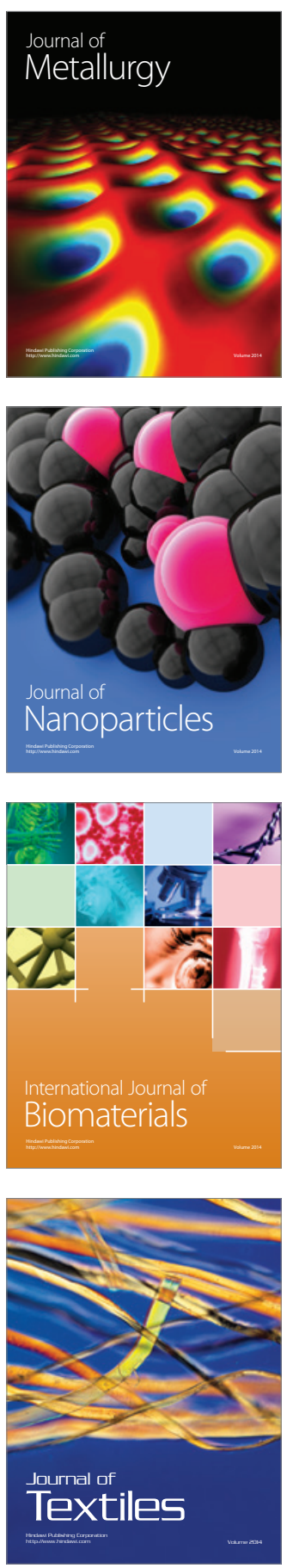